\title{
Population-Based Estimation of Dental Caries and Periodontal Disease Rates of Gravid and Recently Postpartum Women in Lilongwe, Malawi
}

\author{
${ }^{1}$ Department of Obstetrics and Gynecology, Baylor College of \\ Medicine, One Baylor Plaza, Houston, Texas \\ ${ }^{2}$ Department of Obstetrics and Gynecology, Division of Maternal- \\ Fetal Medicine, One Baylor College of Medicine, Houston, Texas \\ ${ }^{3}$ Department of Obstetrics and Gynecology, Division of Maternal-Fetal \\ Medicine, University of Wisconsin-Madison, Madison, Wisconsin \\ ${ }^{4}$ Department of Pediatrics, Baylor College of Medicine Children's Clinical \\ Center of Excellence, Kamuzu Central Hospital, Lilongwe, Malawi \\ ${ }^{5}$ Dental Department, Kamuzu Central Hospital, Lilongwe, Malawi \\ ${ }^{6}$ Department of Obstetrics and Gynecology, Kamuzu Central \\ Hospital, Lilongwe, Malawi \\ ${ }^{7}$ St. Olaf College, Northfield, Minnesota \\ ${ }^{8}$ American Board of Obstetrics and Gynecology, 2915 Vine Street, \\ Dallas, Texas
}

Kathleen M. Antony, MD, MSCI ${ }^{1,2,3}$ Peter N. Kazembe, MBChB ${ }^{4}$ Ryan M. Pace, $\mathrm{PhD}^{1}$ Judy Levison, MD, MPH ${ }^{1}$ Jesse Mlotha-Namarika, DDS $^{5}$ Henry Phiri, MD ${ }^{6}$ Grace Chiudzu, MD R. Alan Harris, $\mathrm{PhD}^{1}$ Joshua Aagaard ${ }^{7}$ Nicholas Twyman, BS ${ }^{1}$ Susan M. Ramin, $\mathrm{MD}^{1,2,8}$ Susan P. Raine, MD ${ }^{1}$ Michael A. Belfort, MD, PhD ${ }^{1,2}$ Kjersti M. Aagaard, MD, PhD ${ }^{1,2}$

Am J Perinatol Rep 2019;9:e268-e274.

\begin{abstract}
Address for correspondence Kathleen M. Antony, MD, MSCI, Department of Obstetrics and Gynecology, Division of Maternal-Fetal Medicine, University of Wisconsin-Madison, 202 South Park Street, Madison, WI 53715-1599 (e-mail: kantony@wisc.edu).
\end{abstract}

\begin{abstract}
Keywords

- pregnancy

- preterm birth

- Malawi

- dental caries

- periodontal disease

- global health

Objectives The objective of this study was to determine the rate of dental caries and periodontal disease among gravid and recently postpartum women at five delivery centers within and surrounding Lilongwe, Malawi.

Study Design We partnered with obstetric specialists, community health workers, and dentists to perform dental history interviews and dental examinations during the study period from December 2012 to May 2014. Dental examinations were performed according to World Health Organization standards to assess periodontal and oral health status.

Results Among the 387 gravid and recently postpartum women, the rate of dental caries was $69.3 \%$ and the rate of composite dental disease (caries and periodontal disease) was $76.7 \%$. The majority (69.5\%) of women examined had a decayed-missing-filled (DMF) index greater than or equal to one; the average DMF Index was 2.48. The majority of women had never seen a dentist (62.8\%). However, most did perform oral hygiene, two or more times per day (90.2\%); most women reported brushing with toothpaste (88.1\%).

Conclusion When assessing this population for dental caries and periodontal disease, the rate of dental disease was high. Therefore, this may be an ideal setting to test for impactful interventions aimed at reducing caries and periodontal disease.
\end{abstract}

(D) Kathleen M. Antony's ORCID is https://orcid.org/0000-00033537-8030.

received

June 1, 2019 accepted after revision June 15, 2019
DOI https://doi.org/

10.1055/s-0039-1695003. ISSN 2157-6998.
Copyright $\odot 2019$ by Thieme Medical Publishers, Inc., 333 Seventh Avenue, New York, NY 10001, USA. Tel: +1(212) 584-4662.
License terms

$\circledast(1) \Theta \circledast$ 
Preterm birth (PTB) is the leading cause of childhood mortality worldwide. ${ }^{1}$ Malawi's PTB rate is high with estimates ranging from 7.9 to $29.7 \%{ }^{2-4}$ While the etiology of PTB is multifactorial, the association of PTB with infection and inflammation is well supported by decades of data. ${ }^{5}$ Although most studies focus on ascending infections from the genital tract, dental caries and periodontal disease have also been associated with PTB, and in many studies have proven to be an independent risk factor for PTB. ${ }^{6-9}$ Proposed mechanisms for this relationship include the inflammation and inflammatory response associated with caries and periodontal disease $\mathrm{e}^{8,10-12}$ and the hematogenous spread of bacteria from the oral cavity to the placenta. ${ }^{11,13-19}$

Given the known association between dental caries and/or periodontal disease and PTB, our primary aim was to measure the rate of dental caries and periodontal disease in the gravid (and recently postpartum) population with detailed and highly specialized dental examinations by in-country personnel and providers. Our hypothesis was that the rate of dental caries and periodontal disease would exceed $50 \%{ }^{20-22}$ We also sought to assess willingness to accept and measure compliance with a dental intervention.

\section{Study Design}

This study was approved by the National Health Sciences Research Committee with the Malawi Ministry of Health (IRB00003905, FWA00005976, NHSRC 1030). This study was conducted in accordance with the Helsinki Declaration as revised in 2013. Baylor College of Medicine in Houston, Texas has collaborated with the Malawi Ministry of Health and the College of Medicine of Malawi to expand obstetrical and antenatal care with a focus on addressing the high rate of PTB in Malawi. This project was undertaken to assess the rate of dental caries and periodontal disease among gravid and recently postpartum women and to assess whether interventions to reduce the burden of dental caries and periodontal disease would be acceptable to the community.

To determine the rate of dental caries and periodontal disease in the gravid population, we partnered with obstetrician specialists, community health workers, local midwives, clinicians, and dentists in a $50 \mathrm{~km}$ region surrounding Lilongwe, Malawi. Health centers at the sites of Kabudula and Area 25 (rural health centers) and the sites of Kawale and Area 18 (urban health centers) along with Kamuzu Central Hospital $(\mathrm{KCH})$, regional referral hospital, were designated as study sites. Primary/community health centers are comprised of outpatient units (including antenatal clinics), holding beds, maternity units, antenatal units, postnatal beds, and holding wards. Community health workers are individuals without formal health training whose role is to educate patients and community members through prepared speeches and songs; they also serve as liaisons with the community leaders to further promote health messages. In this study, the community health workers assisted with recruiting gravid and recently delivered postpartum women for dental assessments and assisted participants with completing the dental health interviews. The midwives and clinical officers, who participated in this project, were all local to the region of study, and the local dentists at the corresponding health center performed all dental examinations.

Data related to dental health interviews and exams were collected between December 21, 2012 and May 19, 2014. Community health workers approached gravid women seeking antenatal care at four local health centers and one referral center; women were invited to participate while waiting for their antenatal clinic visit and the full interview and examination occurred after their clinical care for the day was completed. Recently postpartum women (prior to discharge from the hospital, typically 24-96 hours of postpartum) were invited to participate following an introduction by their clinical officer if they were deemed safe to leave the postpartum unit for a dental examination. Inclusion criteria included that the gravidae have either a confirmed pregnancy or have recently given birth at the hospital or health center where the studies were occurring. For the purpose of this study, there were no exclusion criteria. Verbal informed consent was obtained from each participating woman by the community health worker. During this interview, they were invited to complete a dental history and be seen in the dental clinic for a dental examination.

Following enrollment and interviews, a dental-history interview and examination were performed. The dental-history interview was read aloud by community health workers who also completed the forms. Participants were asked how they cleaned their teeth (e.g., toothpaste, charcoal, chewstick/miswak [a common name for twigs used for cleaning teeth]) and the frequency with which they cleaned their teeth. Other questions queried whether they had ever seen a dentist and whether they had dental symptoms, such as bleeding gums. A trained dental officer performed the dental examinations of participants using Malawi Ministry of Health guidelines, which are in accordance with the World Health Organization guidelines; the status of each tooth was evaluated for caries, gingival bleeding, dental pockets, fluorosis, erosion, and traumatic injuries, and the status of the mucosa was also noted. The decayed-missing-filled (DMF) index was calculated. ${ }^{23}$ A composite dental score was also created; this composite dental score was positive if any of the following were detected: (1) caries, (2) gingival bleeding, (3) pockets of $4 \mathrm{~mm}$ or greater, (4) dental erosion, or (5) oral mucosal abnormalities.

We also assessed women's willingness to use various dental interventions, initially via focus groups with a different population of women (reported separately) ${ }^{24}$ and also during the dental history interview. Based upon our focus group results, ${ }^{24}$ xylitol gum was chosen as a dental intervention to pilot at the rural health centers (Kabudula and Area 25), and compliance with the dental intervention was assessed.

Data were entered in real time directly into a deidentified centralized web-based survey tool which allows for local data entry in Malawi and distant data export and analysis in the United States. (SurveyMonkey Inc., Palo Alto, CA, www.surveymonkey.com).

As this was a population-based assessment to measure the rate of dental caries and periodontal disease in Lilongwe, Malawi, and the surrounding area, no sample size calculation was performed. Descriptive statistics are reported. Chi-square, 
Fisher's exact test, and the Student's $t$-test were performed where appropriate. All statistical analyses were performed using SPSS 25.0 (IBM Corporation. Released 2017. IBM SPSS Statistics for Windows, Armonk, NY).

\section{Results}

During the study period from December 21, 2012 through May 19, 2014, 387 women (384 gravid and three recently postpartum) agreed to participate in the dental history interview; 384 completed the detailed dental examination (three women completed the dental interview but were discharged and had to return home prior to completing the dental examination). Follow-up examinations and interviews were completed among 200 women.

Demographic characteristics of the women participating are shown in -Table 1. Limited demographic data were collected with the dental history. The average age of participants was 25.2 years and did not vary significantly by site designation of rural, urban, or referral center. The ethnic composition varied by site, as did the participants' occupation, and years of formal education. The average gestational age at the time of the initial dental interview and examination was 5.93 months (self-reported in months).

The majority of women had never previously seen a dentist (62.8\%). Of those who had seen a dentist, most had not seen one in 1 to 2 years. The most common method of oral hygiene was brushing with toothpaste (88.1\%). Significantly less women seen at urban health centers used rinsing as a method of oral hygiene ( $p$ 0.026), and only $0.5 \%$ of women reported using gum, mints, or candies for oral hygiene.

Dental data for oral health and rates of dental caries and periodontal disease are shown in - Table 2. The majority (69.5\%) of women examined had a DMF index greater than or

Table 1 Demographic data

\begin{tabular}{|c|c|c|c|c|c|}
\hline Characteristic & $\%$ or mean & $\begin{array}{l}\text { Rural health centers } \\
\text { (Area } 25 \text { and Kabudula) }\end{array}$ & $\begin{array}{l}\text { Urban health centers } \\
\text { (Area } 18 \text { and Kawale) }\end{array}$ & $\begin{array}{l}\text { Kamuzu } \\
\text { central } \\
\text { hospital }\end{array}$ & \\
\hline Total & 100.0 & $(n=218)$ & $(n=161)$ & $(n=8)$ & $p$-Value \\
\hline Age (y): mean, (SD) & $25.2(5.8)$ & $24.9(5.8)$ & $25.4(5.8)$ & $28.9(2.7)$ & 0.13 \\
\hline $\begin{array}{l}\text { Gestational age (mo): } \\
\text { mean, }(\mathrm{SD})^{\mathrm{a}}\end{array}$ & $5.93(1.57)$ & $5.97(1.54)$ & $5.89(1.62)$ & $5.63(1.41)$ & 0.76 \\
\hline \multicolumn{6}{|l|}{ Ethnic group $(n, \%)^{\mathrm{b}}$} \\
\hline Chewa & $220(56.8)$ & $160(73.4)$ & $58(36.0)$ & $2(25.0)$ & \\
\hline Lomwe & $32(8.3)$ & $7(3.2)$ & $24(14.9)$ & $1(12.5)$ & \\
\hline Mang'anja & $3(0.8)$ & $2(0.9)$ & $1(0.6)$ & $0(0)$ & \\
\hline Ndali & $1(0.3)$ & $0(0)$ & $1(0.6)$ & $0(0)$ & \\
\hline Ngoni & $53(13.7)$ & $13(6.0)$ & $37(23.0)$ & $3(37.5)$ & \\
\hline Nyanja & $3(0.8)$ & $0(0)$ & $3(1.9)$ & $0(0)$ & \\
\hline Sena & $6(1.6)$ & $3(1.4)$ & $3(1.9)$ & $0(0)$ & \\
\hline Tonga & $5(1.3)$ & $4(1.8)$ & $1(0.6)$ & $0(0)$ & \\
\hline Tumbaka & $15(3.9)$ & $5(2.3)$ & $9(5.6)$ & $1(12.5)$ & \\
\hline Yao & $22(5.7)$ & $5(2.3)$ & $16(9.9)$ & $1(12.5)$ & $<0.001$ \\
\hline Years in school (mean, SD) & $8.0(4.7)$ & $6.8(4.1)$ & $9.1(4.9)$ & $15(4.0)^{c}$ & $<0.001$ \\
\hline \multicolumn{6}{|l|}{ Occupation $(n, \%)^{d}$} \\
\hline Business & $22(5.7)$ & $0(0)$ & $18(11.2)$ & $4(50)$ & \\
\hline Education & $5(1.3)$ & $0(0)$ & $5(3.1)$ & $0(0)$ & \\
\hline Farmer & $68(17.6)$ & $62(28.4)$ & $6(3.7)$ & $0(0)$ & \\
\hline Health care worker (any type) & $6(1.6)$ & $4(1.8)$ & $2(1.2)$ & $0(0)$ & \\
\hline Housewife & $112(28.9)$ & $76(34.9)$ & $36(22.4)$ & $0(0)$ & \\
\hline Laborer & $5(1.3)$ & $1(0.5)$ & $4(2.5)$ & $0(0)$ & \\
\hline Police officer & $2(0.5)$ & $0(0)$ & $1(0.6)$ & $1(12.5)$ & $<0.001$ \\
\hline
\end{tabular}

Abbreviation: SD, standard deviation.

Note: Chi-square test or Fisher's Exact test performed for categorical variables, $t$-test for continuous variables.

${ }^{a}$ Gestational age was by participants' self-report in months.

bMany did not report an Ethnic Group.

'Several delivering at Kamuzu Central Hospital had college or doctoral degrees.

${ }^{\mathrm{d}}$ Many did not report an occupation. 
Table 2 Dental history and examination findings

\begin{tabular}{|c|c|c|c|c|c|}
\hline Characteristic & $\%$ or mean & $\begin{array}{l}\text { Rural health } \\
\text { centers }\end{array}$ & $\begin{array}{l}\text { Urban health } \\
\text { centers }\end{array}$ & $\begin{array}{l}\text { Kamuzu } \\
\text { central } \\
\text { hospital }\end{array}$ & \\
\hline Total & 100.0 & $(n=218)$ & $(n=161)$ & $(n=8)$ & p-Value \\
\hline History of never having seen a dentist ( $n, \%)$ & $243(62.8)$ & $147(67.4)$ & $93(57.8)$ & $3(37.5)$ & 0.051 \\
\hline \multicolumn{6}{|l|}{ Timing since prior dental visit } \\
\hline Less than $6 \mathrm{mo}$ & $18(4.7)$ & $12(5.5)$ & $6(3.7)$ & $0(0)$ & \\
\hline $6-12 \mathrm{mo}$ & $21(5.4)$ & $11(5.0)$ & $10(6.2)$ & $0(0)$ & \\
\hline $1-2 y$ & $43(11.1)$ & $19(8.7)$ & $21(13.0)$ & $3(37.5)$ & \\
\hline $2-5 y$ & $30(7.8)$ & $14(6.4)$ & $16(9.9)$ & $0(0)$ & \\
\hline More than $5 y$ & $32(8.3)$ & $15(6.9)$ & $15(9.3)$ & $2(25.0)$ & 0.096 \\
\hline \multicolumn{6}{|l|}{ Method of oral hygiene $(n, \%)$} \\
\hline Rinsing & $38(9.8)$ & $29(13.3)$ & $8(5.0)$ & $1(12.5)$ & 0.026 \\
\hline Brushing with toothpaste & $341(88.1)$ & $185(84.9)$ & $148(91.9)$ & $8(100)$ & 0.064 \\
\hline Finger with toothpaste & $12(3.1)$ & $9(4.1)$ & $3(1.9)$ & $0(0)$ & 0.398 \\
\hline Chewstick/miswak & $25(6.5)$ & $16(7.3)$ & $9(5.6)$ & $0(0)$ & 0.597 \\
\hline Dental floss & $1(0.3)$ & $1(0.5)$ & $0(0)$ & $0(0)$ & 0.678 \\
\hline Ash and dirt & $1(0.3)$ & $1(0.5)$ & $0(0)$ & $0(0)$ & 0.678 \\
\hline Toothpick (wooden or plastic) & $1(0.3)$ & $0(0)$ & $1(0.6)$ & $0(0)$ & 0.495 \\
\hline Gum, mint, or candy & $2(0.5)$ & $2(0.9)$ & $0(0)$ & $0(0)$ & 0.459 \\
\hline \multicolumn{6}{|l|}{ Frequency of oral hygiene $(n, \%)$} \\
\hline Two or more times per day & $349(90.2)$ & $193(88.5)$ & $148(91.9)$ & $8(100)$ & \\
\hline Once per day & $36(9.3)$ & $24(11.0)$ & $12(7.5)$ & $0(0)$ & \\
\hline More than once per week & $1(0.3)$ & $1(0.5)$ & $0(0)$ & $0(0)$ & \\
\hline Less than once per week & $1(0.3)$ & $0(0)$ & $1(0.6)$ & $0(0)$ & 0.622 \\
\hline \multicolumn{6}{|l|}{ Dental scores } \\
\hline DMF Index $\geq 1(n, \%)$ & $269(69.5)$ & $148(67.9)$ & $115(71.4)$ & $6(75.0)$ & 0.72 \\
\hline DMF Index & $2.48(2.81)$ & $2.27(2.53)$ & $2.79(3.17)$ & $2.13(1.81)$ & 0.19 \\
\hline Number of decayed teeth (mean, SD) & $1.53(1.98)$ & $1.39(1.86)$ & $1.75(2.15)$ & $1.13(1.24)$ & 0.18 \\
\hline Number of missing teeth (mean, SD) & $0.96(1.44)$ & $0.86(1.25)$ & $1.12(1.68)$ & $0.63(0.74)$ & 0.18 \\
\hline Number of filled teeth (mean, SD) & $0.06(0.53)$ & $0.07(0.62)$ & $0.05(0.29)$ & $0.38(1.06)$ & 0.22 \\
\hline Active caries present $(n, \%)$ & $268(69.3)$ & $148(67.9)$ & $115(71.4)$ & $5(62.5)$ & 0.70 \\
\hline Gingival bleeding present $(n, \%)$ & $147(38.0)$ & $80(36.7)$ & $64(39.8)$ & $3(37.5)$ & 0.83 \\
\hline Pockets present $(n, \%)$ & $124(32.0)$ & $67(30.7)$ & $56(34.8)$ & $1(12.5)$ & 0.34 \\
\hline Erosion present $(n, \%)$ & $7(1.8)$ & $3(1.4)$ & $4(2.5)$ & $0(0)$ & 0.67 \\
\hline Abnormal mucosa $(n, \%)$ & $2(0.5)$ & $1(0.5)$ & $1(0.6)$ & $0(0)$ & 0.96 \\
\hline Composite dental score positive $(n, \%)$ & $297(76.7)$ & $164(75.2)$ & $127(78.9)$ & $6(75.0)$ & 0.703 \\
\hline
\end{tabular}

Abbreviations: DMF index, decayed-missing-filled index; SD, standard deviation.

Note: Chi-square test or Fisher's exact test performed for categorical variables, $t$-test for continuous variables.

equal to 1 (95\% confidence interval [CI]: 64.9-74.1\%); the average DMF index was 2.48 (95\% CI: 2.20-2.76). Regarding the composite dental assessment, $76.7 \%$ (95\% CI: 72.5-81.0\%) had composite dental disease (comprised of caries and or/ periodontal disease); 69.3\% (95\% CI: 64.7-73.8\%) of women had caries, $38.0 \%$ (95\% CI: 33.1-42.8\%) of women had gingival bleeding, 32.0\% (95\% CI: 27.4-36.7\%) of women had pockets (greater than $4 \mathrm{~mm}$ ), $1.8 \%$ (95\% CI: $0.5-3.1 \%$ ) of women had dental erosions, and $0.5 \%$ (95\% CI: $0.0-1.2 \%$ ) had mucosal abnormalities. In the rural health centers, 75.2\% (95\% CI: 69.5-81.0\%) of women had caries and/or periodontal disease; in the urban health centers, 78.9\% (95\% CI: 72.6-85.2\%) of women had caries and/or periodontal disease; at $\mathrm{KCH}$, 75.0\% (95\% CI: $45.0-100 \%$ ) had caries and/ or periodontal disease. The rates of caries and periodontal disease did not vary by site. 
Regarding women's willingness to use dental interventions, we queried whether women would be willing to use xylitol-containing gum, mint, or candy with the option of choosing any or all methods that they would be willing to use. Gum was the most commonly accepted intervention (66.1\%). Mint and candy were accepted by only 26.6 and $10.6 \%$ of women, respectively. We, therefore, distributed gum to the rural health centers to assess compliance. Two hundred women presented for follow-up dental examinations (88 from the rural health centers and 112 from the urban health centers). Forty-two of these women were postpartum at the time of follow-up examination. Of the women who were still pregnant at the time of the follow-up examination, the average gestational age was 6.74 months (self-reported in months). Where gum was distributed, $100 \%$ women reported using the gum at least once a day, and $92.0 \%$ women reported using the gum twice daily, as recommended.

\section{Discussion}

When performing a population-based estimation of the rate of composite dental disease of gravid and recently postpartum women at selected sites in a $50 \mathrm{~km}$ region surrounding Lilongwe, Malawi, the rate was 76.7\%; among them, $69.5 \%$ women had a DMF index greater than or equal to one. This oral disease was mostly comprised of dental caries, but a significant number of women also demonstrated periodontal disease with gingival bleeding and pockets.

While the majority of women had not seen a dentist, most did perform oral hygiene by brushing with toothpaste (88.1\%) and reported performing this hygiene twice or more daily. A minority used rinses (less in urban settings) and of the whole population, only two $(0.5 \%)$ used gum, mints, or candies for oral hygiene. Our dental examination findings are congruous with those of prior investigators who estimate that $85.4 \%$ of pregnant women in Malawi have some degree of dental caries and/or periodontal disease with over $50 \%$ demonstrating caries and $23.5 \%$ having periapical infections..$^{20-22}$ These investigators notably found that pregnancies with periapical infections were shorter in duration than those without such infections. ${ }^{21}$

Several studies and meta-analyses have demonstrated promise in improving perinatal outcomes, notably PTB, by treating dental caries and/or periodontal disease, ${ }^{25,26}$ although more recent studies and meta-analyses have not demonstrated clear benefit in terms of PTB. ${ }^{27}$ However, treatment does appear to improve maternal oral health, and, importantly, does not increase the risk of PTB. ${ }^{27-29}$ It may be that treatment only decreases PTB if disease improves, ${ }^{30}$ or it may be that treatment during pregnancy is too late, but treatment in the prepregnancy or interpregnancy period is beneficial. ${ }^{31}$ However, many low and middle income countries (LMICs) have a shortage of qualified dental providers to perform invasive interventions; here, we demonstrated that the majority of patients had not previously seen a dentist. Therefore, a practical, easy to distribute, and simple to use dental intervention, which did not require clean water, was sought.
Our next step was to assess whether women were willing to use such an intervention in addition to the oral hygiene, they were already using. Xylitol has been shown to decrease dental caries, the decay-missing-filled index/score (DMF index or DMFS), and decrease inflammation: traits which are partly attributed to the oral microflora's inability to metabolize it. Through prestudy focus groups, we queried whether gum, lozenges, or lollipops would be preferable, and gum was preferred. ${ }^{24}$ When this intervention was distributed, among women returning for a return dental visit, compliance was high with $92.0 \%$ of women reporting usage of twice daily. These findings suggest that, if such an intervention were utilized to target reduction in oral disease in pregnant women (and possible thereby reduce PTB), this intervention would be acceptable and compliance rates may also be acceptable.

Strengths of this study include the fact that all dental examinations were completed by trained dental officers in accordance with World Health Organization standards. Potential strengths also include the fact that compliance with the follow-up dental examination was reasonably high at $51.7 \%$. Compliance with the intervention (xylitol-containing gum) was high as well. Thus, future studies that seek to intervene with these agents may anticipate similarly high rates of compliance.

This study has significant limitations. No obstetric data were obtained during the dental history interview; therefore, we are not able to correlate the dental findings with the participants' obstetric outcomes. The majority of women in this study were pregnant at the time of the dental interview, thus obstetric outcomes had not yet occurred. However, the relationship between caries and/or periodontal disease and PTB has been thoroughly explored in prior studies. ${ }^{6,8,9,21}$ Other limitations include the fact that significantly more women sought antenatal care and birthed during this time period than agreed to present for the dental interview (due to location outside the area of the antenatal clinic and general maternity ward and occasionally long wait times), so our sample population may not be representative of the overall population of women delivering at these centers. Indeed, the rate of oral disease in this study is slightly lower than seen by other investigators. ${ }^{20-22}$ Other limitations include the use of the DMF index, which has been reported to underestimate the real prevalence of caries and need for treatment. Finally, the assessment of compliance was self-reported. Counting the remaining pieces of gum could improve the reliability of this assessment but does not ensure that the gum was used as directed or that other individuals were not also using the gum.

\section{Conclusion}

In conclusion, we demonstrated that the rate of composite dental disease among sampled pregnant or recently postpartum women within and surrounding Lilongwe, Malawi, is high, at $76.7 \%$. While the etiology of PTB is multifactorial, in this population, dental caries and periodontal disease is potentially a significant contributor. The acceptance of and compliance with the use of xylitol gum, as an intervention, was also high in this population. Therefore, Lilongwe, 
Malawi, may be an ideal setting for future trials investigating the efficacy of xylitol-containing gum as an intervention to reduce $\mathrm{PTB}$.

\section{Financial Support}

USAID/Bill \& Melinda Gates Foundation Saving Lives at Birth Grand Challenges Grant: AID-OAA-G-11-00062. (K. Aagaard); E.W. Al Thrasher Foundation (K. Aagaard); March of Dimes Prematurity Research Initiative (K. Aagaard, S. Raine); NIH K12 GM084897 by National Institute of Health (R. Pace).

\section{Paper Presentation Information}

Data from this paper were presented as a poster presentation at the Society of Maternal-Fetal Medicine's 34th Annual Meeting-The Pregnancy Meeting, New Orleans, LA, February 3-8, 2014, Abstract Number 522 and the Society of Maternal-Fetal Medicine's $36^{\text {th }}$ Annual Meeting-The Pregnancy Meeting, Atlanta, GA, February 1-6, 2016, Abstract Number 549.

\section{Conflict of Interest Statement}

The authors have stated explicitly that there are no conflicts of interest in connection with this article.

\section{Acknowledgments}

We would like to thank the Bill \& Melinda Gates Foundation, the E.W. Al Thrasher Foundation, the March of Dimes, and the USAID for their financial support. We would like to thank the pregnant and postpartum women for agreeing to participate in this study. We would like to acknowledge Debora Nanthuru and Bertha Banda for their excellent leadership, guidance, and language and cultural skills, and the research project managers for this project in Lilongwe, Malawi. This project was made possible through the efforts of Rose Chirwa, Mary Nyondo, Ellina Marko, and Andrew Chigayo who are community health workers in Malawi, for their subject matter expertise and for coordinating the focus group sessions. We appreciate the expertise of the local dentists (Alidi Chigomanje, Bernard Chilongo, Collins Phiri, Gerald Chongo, Gian Somante, Halmiton Kasakula, Kondwani Chisi, Mike Ndau, Pax Chalira, and Winiwa Gondwe). We would like to also acknowledge Robert Koehler, medical librarian, with UnityPoint Health-Meriter, for his assistance with reviewing the literature and procuring articles.

\section{References}

1 Liu L, Johnson H, Cousens S. Global, regional, and national causes of child mortality: an updated systematic analysis for 2010 with time trends since 2000. Lancet 2012;379(9832):2151-2161

2 van den Broek N, Ntonya C, Kayira E, White S, Neilson JP. Preterm birth in rural Malawi: high incidence in ultrasound-dated population. Hum Reprod 2005;20(11):3235-3237

3 Stewart CP, Oaks BM, Laugero KD, et al. Maternal cortisol and stress are associated with birth outcomes, but are not affected by lipid-based nutrient supplements during pregnancy: an analysis of data from a randomized controlled trial in rural Malawi. BMC Pregnancy Childbirth 2015;15(346):346
4 van den Broek NR, Jean-Baptiste R, Neilson JP. Factors associated with preterm, early preterm and late preterm birth in Malawi. PLoS One 2014;9(03):e90128

5 Romero R, Dey SK, Fisher SJ. Preterm labor: one syndrome, many causes. Science 2014;345(6198):760-765

6 Khader YS, Ta'ani Q. Periodontal diseases and the risk of preterm birth and low birth weight: a meta-analysis. J Periodontol 2005; 76(02):161-165

7 Offenbacher S, Lin D, Strauss R, et al. Effects of periodontal therapy during pregnancy on periodontal status, biologic parameters, and pregnancy outcomes: a pilot study. J Periodontol 2006;77(12): 2011-2024

8 Pozo E, Mesa F, Ikram MH, et al. Preterm birth and/or low birth weight are associated with periodontal disease and the increased placental immunohistochemical expression of inflammatory markers. Histol Histopathol 2016;31(02):231-237. Doi: 10.14670/HH-11-671

9 American College of Obstetricians and Gynecologists Women's Health Care Physicians; Committee on Health Care for Underserved Women. Committee Opinion No. 569: oral health care during pregnancy and through the lifespan. Obstet Gynecol 2013; 122(2, Pt. 1):417-422

10 Madianos PN, Bobetsis YA, Offenbacher S. Adverse pregnancy outcomes (APOs) and periodontal disease: pathogenic mechanisms. J Periodontol 2013;84(4, Suppl.):S170-S180

11 Puertas A, Magan-Fernandez A, Blanc V, et al. Association of periodontitis with preterm birth and low birth weight: a comprehensive review. J Matern Fetal Neonatal Med 2018;31(05):597-602

12 Horton AL, Boggess KA, Moss KL, Beck J, Offenbacher S. Maternal periodontal disease and soluble fms-like tyrosine kinase-1 expression. J Periodontol 2009;80(09):1506-1510

13 Fardini Y, Chung P, Dumm R, Joshi N, Han YW. Transmission of diverse oral bacteria to murine placenta: evidence for the oral microbiome as a potential source of intrauterine infection. Infect Immun 2010;78(04):1789-1796

14 Han YW, Redline RW, Li M, Yin L, Hill GB, McCormick TS. Fusobacterium nucleatum induces premature and term stillbirths in pregnant mice: implication of oral bacteria in preterm birth. Infect Immun 2004;72(04):2272-2279

15 Han YW, Ikegami A, Bissada NF, Herbst M, Redline RW, Ashmead GG. Transmission of an uncultivated Bergeyella strain from the oral cavity to amniotic fluid in a case of preterm birth. J Clin Microbiol 2006;44(04):1475-1483

16 Aagaard K, Ma J, Antony KM, Ganu R, Petrosino J, Versalovic J. The placenta harbors a unique microbiome. Sci Transl Med 2014;6 (237):237ra65

17 Blanc V, O’Valle F, Pozo E, Puertas A, León R, Mesa F. Oral bacteria in placental tissues: increased molecular detection in pregnant periodontitis patients. Oral Dis 2015;21(07):905-912

18 Han YW, Fardini Y, Chen C, et al. Term stillbirth caused by oral Fusobacterium nucleatum. Obstet Gynecol 2010;115(2, Pt. 2):442-445

19 Lin D, Moss K, Beck JD, Hefti A, Offenbacher S. Persistently high levels of periodontal pathogens associated with preterm pregnancy outcome. J Periodontol 2007;78(05):833-841

20 Shaw L, Harjunmaa U, Doyle R, et al. Distinguishing the Signals of Gingivitis and Periodontitis in Supragingival Plaque: a CrossSectional Cohort Study in Malawi. Appl Environ Microbiol 2016;82(19):6057-6067

21 Harjunmaa U, Järnstedt J, Alho L, et al. Association between maternal dental periapical infections and pregnancy outcomes: results from a cross-sectional study in Malawi. Trop Med Int Health 2015;20(11):1549-1558

22 Harjunmaa U, Järnstedt J, Dewey KG, et al. Nutrient supplementation may adversely affect maternal oral health-a randomised controlled trial in rural Malawi. Matern Child Nutr 2016;12(01):99-110

23 Broadbent JM, Thomson WM. For debate: problems with the DMF index pertinent to dental caries data analysis. Community Dent Oral Epidemiol 2005;33(06):400-409 
24 Levison J, Nanthuru D, Chiudzu G, et al. Qualitative assessment of attitudes and knowledge on preterm birth in Malawi and within country framework of care. BMC Pregnancy Childbirth 2014;14 $(01): 123$

25 George A, Shamim S, Johnson M, et al. Periodontal treatment during pregnancy and birth outcomes: a meta-analysis of randomised trials. Int J Evid-Based Healthc 2011;9(02):122-147

26 Kim AJ, Lo AJ, Pullin DA, Thornton-Johnson DS, Karimbux NY. Scaling and root planing treatment for periodontitis to reduce preterm birth and low birth weight: a systematic review and meta-analysis of randomized controlled trials. J Periodontol 2012;83(12):1508-1519

27 Polyzos NP, Polyzos IP, Zavos A, et al. Obstetric outcomes after treatment of periodontal disease during pregnancy: systematic review and meta-analysis. BMJ 2010;341:c7017
28 Michalowicz BS, Hodges JS, DiAngelis AJ, et al; OPT Study. Treatment of periodontal disease and the risk of preterm birth. $\mathrm{N}$ Engl J Med 2006;355(18):1885-1894

29 Geisinger ML, Geurs NC, Bain JL, et al. Oral health education and therapy reduces gingivitis during pregnancy. J Clin Periodontol 2014;41(02):141-148

30 Jeffcoat M, Parry S, Sammel M, Clothier B, Catlin A, Macones G. Periodontal infection and preterm birth: successful periodontal therapy reduces the risk of preterm birth. BJOG 2011;118(02): 250-256

31 Xiong X, Buekens P, Goldenberg RL, Offenbacher S, Qian X. Optimal timing of periodontal disease treatment for prevention of adverse pregnancy outcomes: before or during pregnancy? Am J Obstet Gynecol 2011;205(02):111.e1-111.e6 